\title{
Aromatic Osmacyclopropenefuran Bicycles and their Relevance for the Metal-Mediated Hydration of Functionalized Allenes
}

María Batuecas, Ruth Castro-Rodrigo, Miguel A. Esteruelas, ${ }^{*}$ Cristina García-Yebra, Ana M. López, and Enrique Oñate

Dedicated to the Memory of Porf. José Barluenga (1940-2016)

[] Dr. M. Batuecas, Dr. R. Castro-Rodrigo, Prof. Dr. M. A. Esteruelas, Dr. C. GarcíaYebra, Prof. Dr. A. M. López, and Dr. E. Oñate

Departamento de Química Inorgánica, Instituto de Síntesis Química y Catálisis Homogénea (ISQCH), Centro de Innovación en Química Avanzada (ORFEO-CINQA) Universidad de Zaragoza-CSIC 50009 Zaragoza, Spain

E-mail: maester@unizar.es

Supporting information for this article is given via a link at the end of the document.

Abstract: The aromatic osmacyclopropenefuran bicycles [OsTp $\left\{\kappa^{3}-C^{1}, C^{2}, O-\right.$ $\left.\left.\left(\mathrm{C}^{1} \mathrm{H}_{2} \mathrm{C}^{2} \mathrm{CHC}(\mathrm{OEt}) \mathrm{O}\right)\right\}\left(\mathrm{P}^{\mathrm{i}} \mathrm{Pr}_{3}\right)\right] \mathrm{BF}_{4}\left(\mathrm{Tp}=\right.$ hydridotris(1-pyrazolyl)borate) and $\left[\mathrm{OsH}\left\{\kappa^{3}-\right.\right.$ $\left.\left.\mathrm{C}^{1}, \mathrm{C}^{2}, \mathrm{O}-\left(\mathrm{C}^{1} \mathrm{H}_{2} \mathrm{C}^{2} \mathrm{CHC}(\mathrm{OEt}) \mathrm{O}\right)\right\}(\mathrm{CO})\left(\mathrm{P}^{\mathrm{i}} \mathrm{Pr}_{3}\right)_{2}\right] \mathrm{BF}_{4}$, with the metal fragment in a common vertex between the fused three- and five-membered rings, have been prepared via the $\pi$-allene intermediates [OsTp $\left.\left(\eta^{2}-\mathrm{CH}_{2}=\mathrm{CCHCO}_{2} \mathrm{Et}\right)\left(\mathrm{OCMe}_{2}\right)\left(\mathrm{PiPr}_{3}\right)\right] \mathrm{BF}_{4}$ and $\left[\mathrm{OsH}\left(\eta^{2}-\right.\right.$ $\left.\left.\mathrm{CH}_{2}=\mathrm{CCHCO}_{2} \mathrm{Et}\right)(\mathrm{CO})\left(\mathrm{OH}_{2}\right)\left(\mathrm{PiPr}_{3}\right)_{2}\right] \mathrm{BF}_{4}$, and their aromaticity analyzed by DFT calculations. The bicycle containing the $\left[\mathrm{OsH}(\mathrm{CO})\left(\mathrm{P}^{\mathrm{i}} \mathrm{Pr}_{3}\right)_{2}\right]^{+}$metal fragment is a key intermediate in the $\left[\mathrm{OsH}(\mathrm{CO})\left(\mathrm{OH}_{2}\right)_{2}\left(\mathrm{P}^{\mathrm{i}} \mathrm{Pr}_{3}\right)_{2}\right] \mathrm{BF}_{4}$-catalyzed regioselective antiMarkovnikov hydration of ethyl buta-2,3-dienoate to ethyl 4-hydroxycrotonate.

Heteroatom-containing metalapolycycles are a class of compounds essential to the understanding of aromaticity. ${ }^{[1]} \pi$-Aromaticity refers to $\pi$-electron conjugation in unsaturated rings whereas $\sigma$-aromaticity is due to $\sigma$-electron delocalization in saturated cycles. ${ }^{[2]} \sigma$-Aromaticity, which was initially proposed to explain the unexpected stability of cyclopropane, ${ }^{[3]}$ has been extended to many other systems with $\sigma$-electron delocalization such as hydrogen clusters, ${ }^{[4]}$ saturated inorganic cycles, ${ }^{[5]}$ metal-hydride clusters ${ }^{[6]}$ hydrocarbon protected metal clusters, ${ }^{[7]}$ all-metal molecules, ${ }^{[8]}$ and metalcarbonyl clusters. ${ }^{[9]}$ Recently, Xia, Zhou, and co-workers have reported $\sigma$-aromaticity in an unsaturated metallacyclopropene unit of cyclopropaosmapentalene complexes. ${ }^{[10]}$ In this communication, we present the first examples of metalacyclopropenefuran bicycles (Scheme 1), which show significant $\sigma$-aromaticity at the three-membered ring and can 
play a main role in the metal-mediated hydration of functionalized allenes, depending upon the $L_{n} M$ unit of the bicycle.

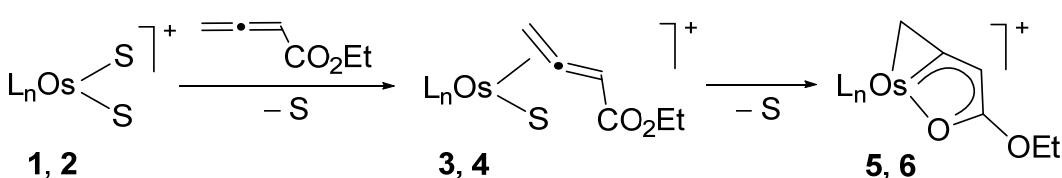

$\mathrm{L}_{n} \mathrm{Os}=\mathrm{OsTp}\left(\mathrm{PiPr}_{3}\right)(\mathbf{1}, \mathbf{3}, \mathbf{5}), \mathrm{OsH}(\mathrm{CO})\left(\mathrm{P}^{\mathrm{i} P r}\right)_{2}(\mathbf{2}, \mathbf{4}, \mathbf{6}) . \mathrm{S}=\mathrm{Me}_{2} \mathrm{CO}(\mathbf{1}, \mathbf{3}), \mathrm{H}_{2} \mathrm{O}(\mathbf{2}, \mathbf{4})$

Scheme 1. Formation of the osmacyclopropenefuran bicycles 5 and $\mathbf{6}$.

One of the solvent molecules of the bis(solvento) complexes $\left[\mathrm{OsTp}\left(\mathrm{OCMe}_{2}\right)_{2}\left(\mathrm{P}^{\mathrm{i}} \mathrm{Pr}_{3}\right)\right] \mathrm{BF}_{4}(1)$ and $\left[\mathrm{OsH}(\mathrm{CO})\left(\mathrm{OH}_{2}\right)_{2}\left(\mathrm{P}^{\mathrm{i}} \mathrm{Pr}_{3}\right)_{2}\right] \mathrm{BF}_{4}(2)$ is displaced by the sterically less hindered double bond of ethyl buta-2,3-dienoate to form the $\eta^{2}$-allene complexes $\left[\mathrm{OsTp}\left(\eta^{2}-\mathrm{CH}_{2}=\mathrm{CCHCO}_{2} \mathrm{Et}\right)\left(\mathrm{OCMe}_{2}\right)\left(\mathrm{P}^{\mathrm{i}} \mathrm{Pr}_{3}\right)\right] \mathrm{BF}_{4}$ (3) and $\left[\mathrm{OsH}\left(\eta^{2}-\right.\right.$ $\left.\left.\mathrm{CH}_{2}=\mathrm{CCHCO}_{2} \mathrm{Et}\right)(\mathrm{CO})\left(\mathrm{OH}_{2}\right)\left(\mathrm{PiPr}_{3}\right)_{2}\right] \mathrm{BF}_{4}$ (4), respectively. The aqua complex 4 was characterized by $\mathrm{X}$-ray diffraction analysis (Figure 1 ). ${ }^{[1]}$ The coordination geometry around the osmium atom can be described as a highly distorted octahedron with pseudotrans phosphines $\left(\mathrm{P}(1)-\mathrm{Os}-\mathrm{P}(2)=145.58(4)^{\circ}\right)$, at opposite sides of an ideal coordination plane, defined by the carbonyl ligand disposed trans to the water molecule $\left(\mathrm{O}(1)-\mathrm{Os}-\mathrm{C}(25)=178.22(17)^{\circ}\right)$ and the hydride ligand disposed trans to the $\mathrm{C}(1)-\mathrm{C}(2)$ double bond of the allene, which situates almost parallel to the $\mathrm{P}(1)-\mathrm{Os}-\mathrm{P}(2)$ direction.

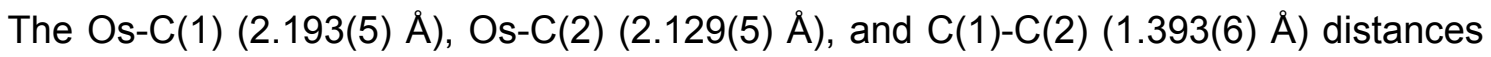
as well as the angles $\mathrm{C}(1)-\mathrm{C}(2)-\mathrm{C}(3)\left(138.5(5)^{\circ}\right)$ and Os-C(2)-C(3) $\left(147.8(4)^{\circ}\right)$ are in agreement with those reported for other osmium- $\eta^{2}$-allene complexes. ${ }^{[12]}$ Consistent with the presence of inequivalent phosphines, the ${ }^{31} \mathrm{P}\left\{{ }^{1} \mathrm{H}\right\}$ NMR spectrum, in THF- $d_{8}$, at $213 \mathrm{~K}$ shows an $\mathrm{AB}$ spin system centered at $\delta 24.8$ and defined by $\Delta v=1026 \mathrm{~Hz}$ and $J_{A-B}=126 \mathrm{~Hz}$. In the ${ }^{1} \mathrm{H}$ NMR spectrum, the hydride ligand displays a double doublet $\left(J_{\mathrm{H}-\mathrm{P}}=J_{\mathrm{H}-\mathrm{P}}=28.1 \mathrm{~Hz}\right)$ at $\delta-2.21$, whereas the resonances corresponding to the coordinated $\mathrm{C}(1)$ and $\mathrm{C}(2)$ atoms appear at $\delta 166.6$ and 15.7, respectively, in the ${ }^{13} \mathrm{C}\left\{{ }^{1} \mathrm{H}\right\}$ NMR spectrum. 


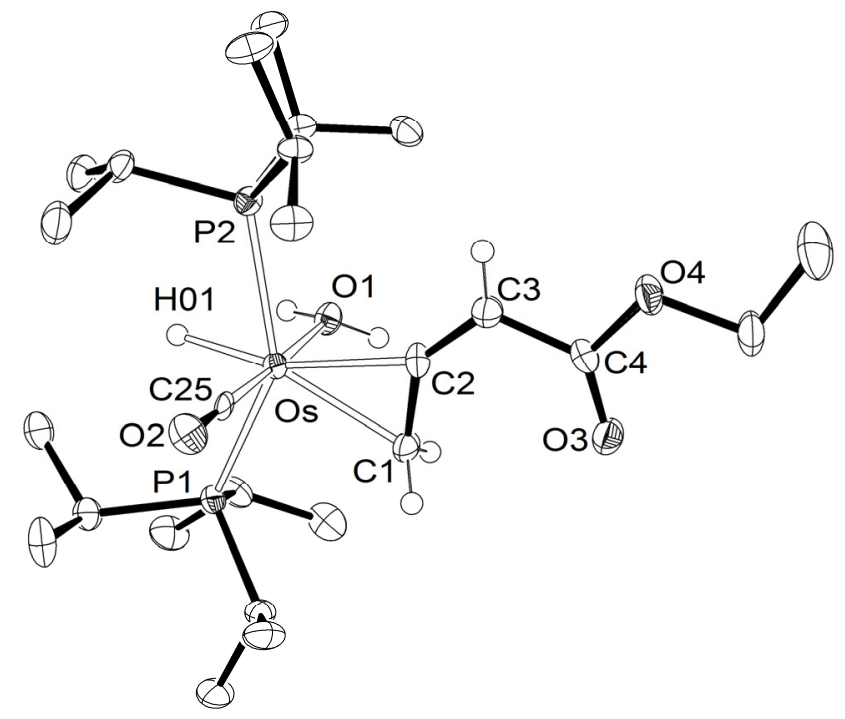

Figure 1. Molecular diagram for the cation of 4 (50\% probability ellipsoids). Selected bond lengths $[\AA]$ and angles [deg]: Os-H01 1.62(4), Os-C1 2.193(5), Os-C2 2.129(5), Os-C25 1.825(5), Os-O1 2.162(3), Os-P1 2.4192(13), Os-P2 2.4292(13), C25-O2 1.169(5), C1-C2 1.393(6), C2-C3 1.337(6); P1-Os-P2 145.58(4), H01-Os-C1 154.9(15), H01-Os-C2 161.3(15), O1-Os-C25 178.22(17), C1-C2-C3 138.5(5), Os-C2-C3 147.8(4).

Complexes 3 and 4 evolve into the heterometalabicycle derivatives [OsTp $\left\{\kappa^{3}-C^{1}, C^{2}, O-\right.$ $\left.\left.\left(\mathrm{C}^{1} \mathrm{H}_{2} \mathrm{C}^{2} \mathrm{CHC}(\mathrm{OEt}) \mathrm{O}\right)\right\}\left(\mathrm{P}^{\mathrm{i}} \mathrm{Pr}_{3}\right)\right] \mathrm{BF}_{4}$ and [OsH $\left\{\kappa^{3}-C^{1}, C^{2}, O\right.$ $\left.\left.\left(\mathrm{C}^{1} \mathrm{H}_{2} \mathrm{C}^{2} \mathrm{CHC}(\mathrm{OEt}) \mathrm{O}\right)\right\}(\mathrm{CO})\left(\mathrm{P}^{\mathrm{i}} \mathrm{Pr}_{3}\right)_{2}\right] \mathrm{BF}_{4}(\mathbf{6})$, as a consequence of the displacement of the second solvent molecule by the carbonyl group of the allene. Complex $\mathbf{5}$ has been characterized by a single crystal X-ray diffraction analysis. Its structure (Figure 2) proves the formation of the heterometalabicycle, which can be regarded as a cyclopropene fused to a furan where a common vertex has been replaced by an [OsTp $\left.\left(\mathrm{P}^{\mathrm{i}} \mathrm{Pr}_{3}\right)\right]^{+}$metal fragment. The coordination polyhedron around the osmium atom can be rationalized as the typical osmium(IV) pentagonal bipyramid with the phosphine and a pyrazolyl group in the axial positions $\left(\mathrm{P}(1)-\mathrm{Os}-\mathrm{N}(5)=175.37(15)^{\circ}\right)$ whereas the bicycle and the other two pyrazolyl groups lie at the equatorial plane. The bicycle is planar. The maximum deviation from the best plane through the atoms $\mathrm{Os}, \mathrm{O}(1), \mathrm{C}(1)$, $C(2), C(3)$, and $C(4)$ is 0.032(4) $\AA$ and involves $O(1)$. The Os-O(1) (2.102(5) $\AA$ ), O(1)$\mathrm{C}(1)(1.261(9) \AA), C(1)-C(2)(1.437(12) \AA), C(2)-C(3)(1.348(11) \AA)$, and $C(3)-O s$ $(1.995(7) \AA)$ bond lengths compare well with those reported for single osmafuran derivatives, ${ }^{[12 a, c, g, 13]}$ whereas the latter along with the $C(3)-C(4)(1.356(11) \AA)$ and the $C(4)$-Os $(2.196(7) \AA)$ distances, which are almost identical to the related Os-C(sp $\left.{ }^{2}\right)$, $\mathrm{C}\left(\mathrm{sp}^{2}\right)-\mathrm{C}\left(\mathrm{sp}^{3}\right)$, and $\mathrm{Os}-\mathrm{C}\left(\mathrm{sp}^{3}\right)$ bond lengths reported for the cyclopropaosmapentalene complexes prepared by Xia and Zhou (1.996(5), 1.376(8), and 2.272(5) $\AA$ and $(1.997(4), 1.396(6)$, and $2.368(4) \AA),{ }^{[10 a]}$ support the osmacyclopropene nature of the three-membered ring. ${ }^{[14]}$ Although for an adequate description of the metalabicycle, the 
resonance structures shown in Chart 1 could be taken into account, the bond lengths suggest that the contributions from I and IV are less important than those from II and III. In agreement with this, the ${ }^{13} \mathrm{C}\left\{{ }^{1} \mathrm{H}\right\}$ NMR spectrum of 5 reveals a significant carbenic character for the Os-C(3) bond. This is strongly supported by the chemical shift of $\mathrm{C}(3)$ resonance, $\delta 232.0$, which is characteristic for aromatic osmacycles ${ }^{[10 a, 12 a, c, g, 13]}$ and is shifted $65.7 \mathrm{ppm}$ towards lower field with regard to the resonance of the analogous carbon atom of its $\eta^{2}$-allene precursor 3 ( $\delta$ 166.3). In accordance with $\mathbf{5}$, the ${ }^{13} \mathrm{C}\left\{{ }^{1} \mathrm{H}\right\}$ NMR spectrum of 6 contains the resonance due to the common carbon atom of the bicycle at $\delta 223.9$, sifted by $57.3 \mathrm{ppm}$ toward lower field with regard to resonance corresponding to the $\mathrm{C}(2)$ atom of 4 . The ${ }^{31} \mathrm{P}\left\{{ }^{1} \mathrm{H}\right\}$ NMR spectrum shows a singlet at $\delta$ 19.8 in accordance with two coplanar fused rings.

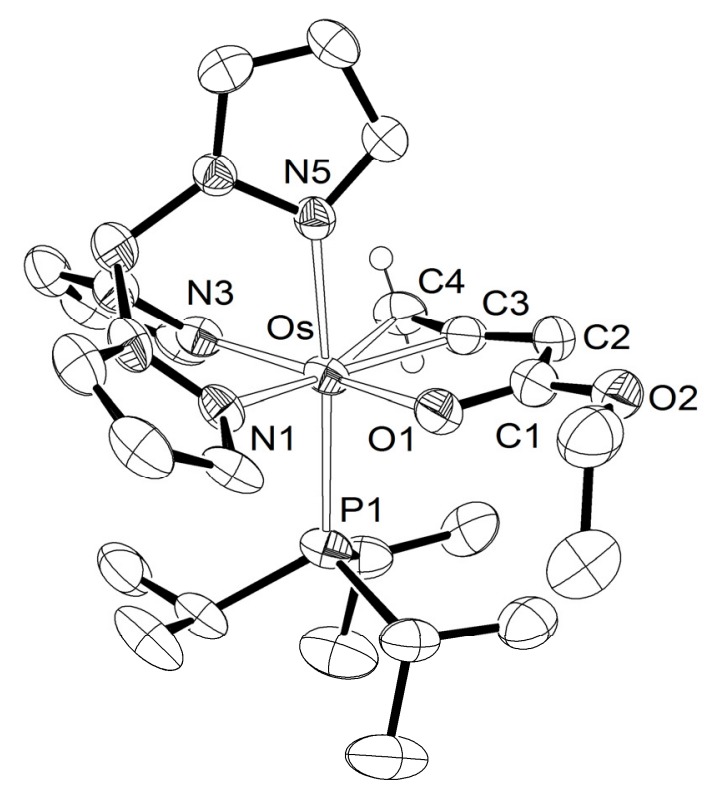

Figure 2. Molecular diagram for the cation of 5 (50\% probability ellipsoids). Selected bond lengths $[\AA]$ and angles [deg]: Os-C3 1.995(7), Os-C4 2.196(7), Os-O1 2.102(5), C3-C4 1.356(11), C2-C3 1.348(11), C1-C2 1.437(12), C1-O1 1.261(9), C1-O2 1.342(9); C3-Os-O1 74.9(3), C3-Os-C4 37.4(3), C2-C3-C4 158.7(8), C2-C3-Os 121.5(6), P1-Os-N5 175.37(15).

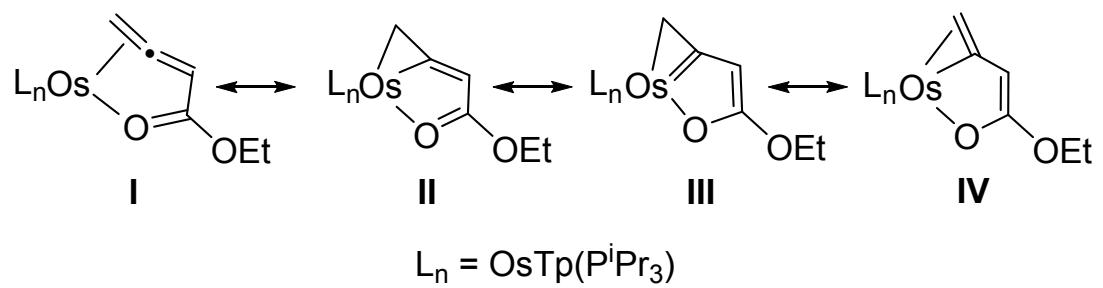

Chart 1. Resonance contributors for the cation of 5. 
The Wiberg bond indices calculated on the optimized structure of the model cation [OsTp $\left.\left\{\kappa^{3}-\mathrm{C}^{1}, \mathrm{C}^{2}, \mathrm{O}-\left(\mathrm{C}^{1} \mathrm{H}_{2} \mathrm{C}^{2} \mathrm{CHC}(\mathrm{OMe}) \mathrm{O}\right)\right\}\left(\mathrm{PH}_{3}\right)\right]^{+}(\mathbf{5 t})$ for the Os-C(4), Os-C(3), and Os$\mathrm{O}(1)$ bonds of 0.61 (0.55 in 5), 0.71 (0.72 in 5) and 0.52 (0.51 in 5), respectively, also reveal that the Os-C(3) interaction has a higher character of double bond than the Os$\mathrm{C}(4)$ and Os-O(1) interactions. This is consistent with the mainly $\mathrm{sp}^{3}$ hybridization calculated for the carbon atom at the Os-C(4) bond (88\% $\mathrm{p}$ orbital component). Calculations of the nucleus-independent chemical shift (NICS $)^{[1 f, 15]}$ on $\mathbf{5 t}$ give negative NICS values. This, along with structural and spectroscopic data, supports the aromatic character of the bicycle. Table 1 collects the isotropic NICS(0) and NICS(1) values, calculated at the center of the rings and at $1 \AA$ above this point, respectively, as well as the dissected NICS $(1)_{z z}$ values, which account for the contributions arising from the $z z$ vector component of the shielding tensor. In agreement with the asymmetry of the molecule, two different values of NICS(1) and NICS(1) zz are given for each ring, syn to the pyrazolyl (pz) group of the Tp ligand and syn to the phosphine ligand. Computed NICS values for the three-membered ring have been found to be more negative than those of the five-membered ring. The highly positive computed electronic energy for the isodesmic reaction shown in Eq. (1) of $28.7 \mathrm{kcal} \mathrm{mol}^{-1}$, involving the cleavage of the C$\mathrm{C}$ bond of the three membered-ring, agrees well with those previously reported for related reactions of the cyclopropaosmapentalene described by Xia and Zhou, ${ }^{10}$ and is an additional evidence in favor of the aromatic character of the three-membered ring. To elucidate the nature of the aromaticity in this ring, we have also performed canonical molecular orbital (CMO) NICS calculations. The total contribution to the $\operatorname{NICS}(0)$ value of the three-membered ring from the key occupied $\pi$ molecular orbitals is $-0.02 \mathrm{ppm}$ whereas that from the key occupied $\sigma$ orbitals is $-37.38 \mathrm{ppm}$ (See Figures S2 and S3), which indicates $\sigma$-aromaticity. The $\sigma$-aromaticity of the threemembered ring is further supported by the anisotropy of the induced current density (AICD) analysis. ${ }^{[16]}$ As shown in Figue 3, the diatropic ring currents in this ring only appear in the $\sigma$ system.

Table 1. Computed NICS for the two fused rings in the model cation $\mathbf{5 t .}$

\begin{tabular}{lll}
\hline & & a \\
\hline $\mathrm{NICS}(0)$ & -50.2 & -4.3 \\
$\mathrm{NICS}(1)$ syn to $\mathrm{pz}$ & -11.0 & -2.5 \\
$\mathrm{NICS}(1)$ syn to $\mathrm{PH}_{3}$ & -16.8 & -4.0 \\
$\mathrm{NICS}(1)_{\mathrm{zz}}$ syn to $\mathrm{pz}$ & -26.0 & -5.4 \\
$\mathrm{NICS}(1)_{\mathrm{zz}}$ syn to $\mathrm{PH}_{3}$ & -28.2 & -4.2 \\
\hline
\end{tabular}




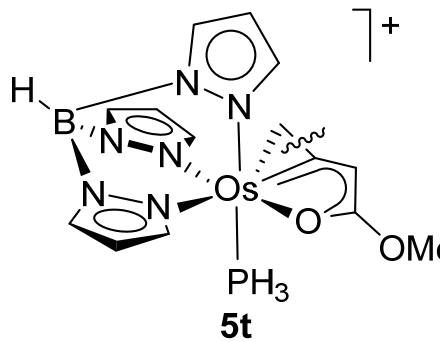

$5 \mathbf{t}$

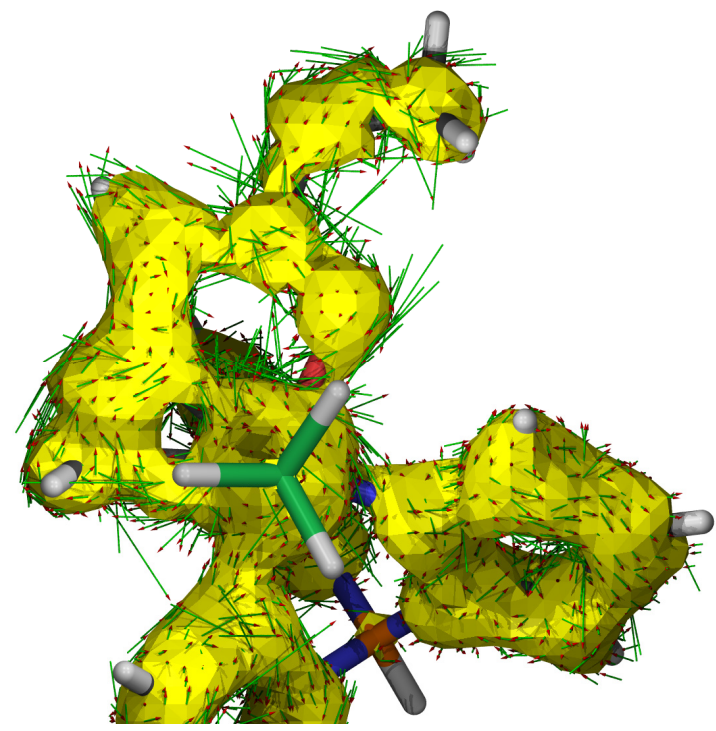

$\sigma$-system

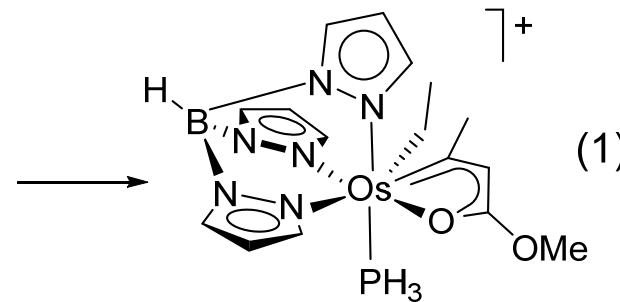

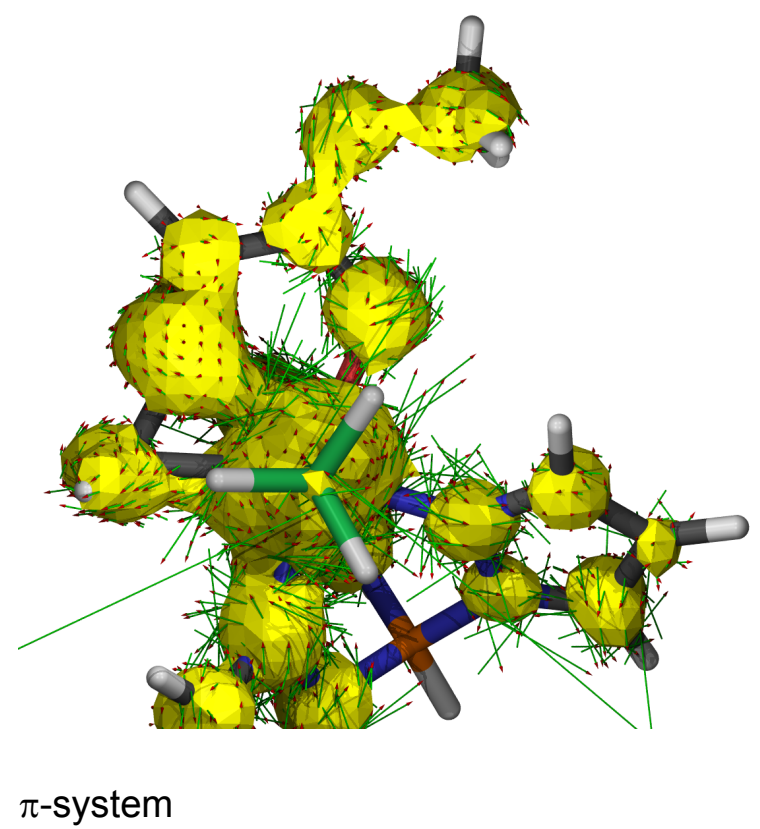

Figure 3. AICD plots of $\mathbf{5 t}$ separated into the $\sigma$ and $\pi$ contributions with an isosurface value of 0.03 . The magnetic field vector is orthogonal with respect to the ring plane and points to the viewer (clockwise currents are diatropic).

The bis(phosphine) complex 6 reacts with water (Eq. (2)), in contrast to its Tp counterpart 5, even though the optimized structures and NICS values suggest a similar bonding situation in both compounds (see Figure S1 and Table S1). Thus, complex 6 can be only isolated as a pure white solid in $73 \%$ yield, starting from the bis(acetone) solvento precursor $\left[\mathrm{OsH}(\mathrm{CO})\left(\mathrm{OCMe}_{2}\right)_{2}\left(\mathrm{P}^{\mathrm{i}} \mathrm{Pr}_{3}\right)_{2}\right] \mathrm{BF}_{4}(\mathbf{2 a})$ under strict absence of water. The reaction with water, which shows a rate comparable to the formation of $\mathbf{6}$ starting from 4, leads to complex $\left[\mathrm{OsH}\left\{\kappa^{3}-\mathrm{C}, \mathrm{C}, \mathrm{O}-\mathrm{CH}\left(\mathrm{CO}_{2} \mathrm{Et}\right)=\mathrm{CHCH} \mathrm{H}_{2} \mathrm{OH}\right\}(\mathrm{CO})\left(\mathrm{P}^{\mathrm{i}} \mathrm{Pr}_{3}\right)_{2}\right] \mathrm{BF}_{4}$ (7), containing a chelating ethyl 4-hydroxycrotonate ligand, resulting from the addition of the water molecule to the three-membered ring of the bicycle. ${ }^{[17]}$ The formation of the allylic alcohol is strongly supported by the ${ }^{1} \mathrm{H},{ }^{13} \mathrm{C}\left\{{ }^{1} \mathrm{H}\right\}$, and ${ }^{31} \mathrm{P}\left\{{ }^{1} \mathrm{H}\right\}$ NMR spectra of the new compound. The ${ }^{1} \mathrm{H}$ NMR spectrum shows a broad signal at $\delta 4.20$ corresponding to the $\mathrm{OH}$-hydrogen atom, whereas the olefinic resonances are observed at $\delta 4.81$ and 4.14. In agreement with the trans disposition of the coordinated $\mathrm{C}-\mathrm{C}$ double bond to the hydride, the spectrum shows a double doublet $\left(J_{\mathrm{H}-\mathrm{P}}=27.7, J_{\mathrm{H}-\mathrm{P}^{\prime}}=27.2 \mathrm{~Hz}\right)$ towards the lower end of the high field region $(\delta-3.63)$. In the ${ }^{13} \mathrm{C}\left\{{ }^{1} \mathrm{H}\right\}$ NMR spectrum, the 
resonances due to the coordinated carbon atoms are observed at $\delta 48.0$ and 43.9. The ${ }^{31} \mathrm{P}\left\{{ }^{1} \mathrm{H}\right\}$ NMR spectrum contains an $A B$ spin system $\left(\Delta v=962 \mathrm{~Hz}, J_{A B}=131 \mathrm{~Hz}\right)$ centered at $\delta 25.2 \mathrm{ppm}$. The difference in behavior between $\mathbf{5}$ and $\mathbf{6}$ may be assigned to the different nature of the OsTp and $\mathrm{OsH}(\mathrm{CO})\left(\mathrm{P}^{\mathrm{i}} \mathrm{Pr}_{3}\right)$ metal fragments. The robustness of the $\mathrm{Tp}$ coordination prevents dissociation processes ${ }^{[18]}$ which are necessary for an inner-sphere metal-mediated water attack.

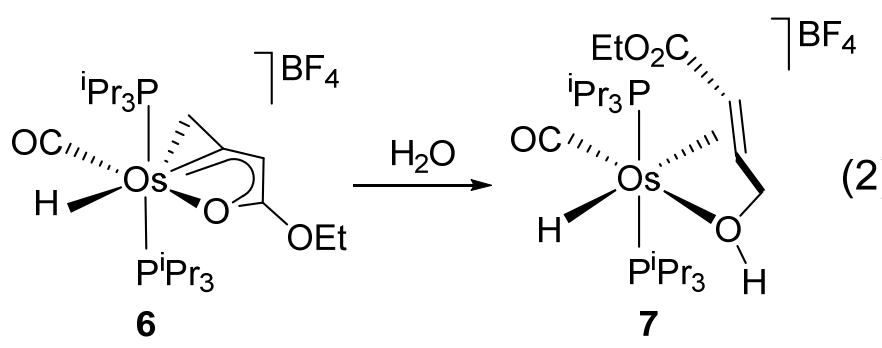

Complexes 4, 6, and 7 are intermediates in the $\mathbf{2}$ mediated regioselective antiMarkovnikov hydration of the unsubstituted $\mathrm{C}-\mathrm{C}$ double bond of ethyl buta-2,3-dienoate to give ethyl 4-hydroxycrotonate (Eq. (3)). In fluorobenzene, at $80^{\circ} \mathrm{C}$, using a $5 \mathrm{~mol} \%$ of catalyst and a 1:5 allenoate/water molar ratio, the transformation is quantitative after $20 \mathrm{~h}$. In this context, it should be pointed out the interest of the allene hydration from an organic synthesis point of view. ${ }^{[19]}$ However, as far as we know, only two catalytic systems have been previously reported. Saito and Wakatsuki have described that the $\mathrm{Ru}_{3}(\mathrm{CO})_{10}$ promotes the formation of metyl- and $\gamma, \delta$-unsaturated ketones, in the presence of trifluoroacetic acid, ${ }^{[20]}$ whereas Widenhoefer and co-workers have shown a gold-mediated generation of allylic alcohols. ${ }^{[21]}$

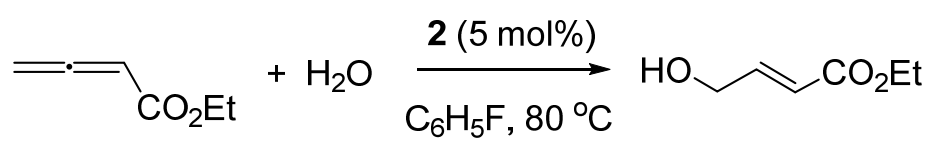

In conclusion, metalacyclopropenefuran compounds have been discovered, isolated in the solid state, characterized by X-ray diffraction analysis and their aromaticity analyzed by DFT calculations. In addition, it is demonstrated that these novel species can be intermediates in the metal-mediated hydration of allenes to allylic alcohols.

\section{Acknowledgements}

Financial support from the MINECO of Spain (Projects CTQ2014-52799-P and CTQ2014-51912-REDC), the Diputación General de Aragón (E-35), FEDER, and the European Social Fund is acknowledged. We thank Prof. Rainer Herges for providing us with the AICD program. 
Keywords: Allenes $\bullet$ aromaticity $\bullet$ hydration $\bullet$ metalaheterobicycle $\bullet$ osmium

\section{References}

[1] a) M. A. Esteruelas, A. B. Masamunt, M. Oliván, E. Oñate, M. Valencia, J. Am. Chem. Soc. 2008, 130, 11612-11613; b) O. Crespo, B. Eguillor, M. A. Esteruelas, I. Fernández, J. García-Raboso, M. Gómez-Gallego, M. Martín-Ortiz, M. Oliván, M. A. Sierra, Chem. Commun. 2012, 48, 5328-5330; c) X.-Y. Cao, Q. Zhao, Z. Lin, H. Xia, Acc. Chem. Res. 2014, 47, 341-354; d) C. Zhu, Q. Zhu, J. Fan, J. Zhu, X. He, X.-Y. Cao, H. Xia, Angew. Chem. Int. Ed. 2014, 53, 6232-6236; e) B. J. Frogley, L. J. Wright, Coord. Chem. Rev. 2014, 270-271, 151-166; f) I. Fernández, G. Frenking, G. Merino, Chem. Soc. Rev. 2015, 44, 6452-6463.

[2] a) P. v. R. Schleyer, Guest Ed. Special issue on Aromaticity. Chem. Rev. 2001, 101 (5); b) P. v. R. Schleyer, Guest Ed. Special issue on Delocalization-Pi and Sigma. Chem. Rev. 2005, 105 (10).

[3] a) M. J. S. Dewar, J. Am. Chem. Soc. 1984, 106, 669-682; b) D. Cremer, J. Gauss, J. Am. Chem. Soc. 1986, 108, 7467-7477.

[4] R. W. A. Havenith, F. D. Proft, P. W. Fowler, P. Geerlings, Chem. Phys. Lett. 2005, 407, 391-396.

[5] a) Z.-H. Li, D. Moran, K.-N. Fan, P. v. R. Schleyer, J. Phys. Chem. A. 2005, 109, 3711-3716; b) N. M. Tam, H. T. Pham, M. T. Nguyen, Chem. Phys. Lett. 2014, 608, 255-263.

[6] X. Zhang, G. Liu, G. Ganteför, K. H. Bowen, A. N. Alexandrova, J. Phys. Chem. Lett. 2014, 5, 1596-1601.

[7] K. Freitag, C. Gemel, P. Jerabek, I. M. Oppel, R. W. Seidel, G. Frenking, H. Banh, K. Dilchert, R. A. Fischer, Angew. Chem. Int. Ed. 2015, 54, 4370-4374.

[8] a) A. I. Boldyrev, L.-S. Wang, Chem. Rev. 2005, 105, 3716-3757; b) C. A. Tsipis, Coord. Chem. Rev. 2005, 249, 2740-2762.

[9] a) R. B. King, Inorg. Chim. Acta 2003, 350, 126-130; b) C.; Corminboeuf, P. v. R. Schleyer, R. B. King, Chem. Eur. J. 2007, 13, 978-984.

[10] a) C. Zhu, X. Zhou, H. Xing, K. An, J. Zhu, H. Xia, Angew. Chem. Int. Ed. 2015, 54, 3102-3106; b) Y. Hao, J. Wu, J. Zhu, Chem. Eur. J. 2015, 21, 18805-18810.

[11] CCDC 1490350 (4) and 1490351 (5) contain the supplementary crystallographic data for this paper. These data can be obtained free of charge from The Cambridge Crystallographic Data via www.ccdc.cam.ac.uk/data_request/cif.

[12] See for example: a) P. Xue, J. Zhu, H. S. Y. Hung, I. D. Williams, Z. Lin, G. Jia, Organometallics 2005, 24, 4896-4898; b) M. A. Esteruelas, Y. A. Hernández, A. M. 
López, E. Oñate, Organometallics 2007, 26, 6009-6013; c) L. Gong, Y. Lin, T. B. Wen, H. Zhang, B. Zeng, H. Xia, Organometallics 2008, 27, 2584-2589; d) R. Castro-Rodrigo, M. A. Esteruelas, A. M. López, S. Mozo, E. Oñate, Organometallics 2010, 29, 4071-4079; e) A. Collado, M. A. Esteruelas, F. López, J. L. Mascareñas, E. Oñate, B. Trillo, Organometallics 2010, 29, 4966-4974; f) R. Castro-Rodrigo, M. A. Esteruelas, A. M. López, E. Oñate, Organometallics 2012, 31, 1991-2000; g) F. Han, T. Wang, J. Li, H. Zhang, L. Zhang, X. He, H. Xia, Organometallics 2014, 33, 5301-5307; h) T. B. Wen, K.-H. Lee, J. Chen, W. Y. Hung, W. Bai, H. Li, H. H. Y. Sung, I. D. Williams, Z. Lin, G. Jia, Organometallics 2016, 35, 1514-1525.

[13] See for example: a) M. A. Esteruelas, Y. A. Hernández, A. M. López, M. Oliván, E. Oñate, Organometallics 2005, 24, 5989-6000; b) M. L. Buil, M. A. Esteruelas, K. Garcés, M. Oliván, E. Oñate, Organometallics 2008, 27, 4680-4690; c) Y. Lin, L. Gong, H. Xu, X. He, T. B. Wen, H. Xia, Organometallics 2009, 28, 1524-1533; d) M. A. Esteruelas, C. Larramona, E. Oñate, Organometallics 2013, 32, 2567-2575; e) J. Chen, Z.-A. Huang, Y. Hua, H. Zhang, H. Xia, Organometallics 2015, 34, 340347; f) J. Alós, M. A. Esteruelas, M. Oliván, E. Oñate, P. Puylaert, Organometallics 2015, 34, 4908-4921.

[14] See for example: a) M. L. Buil, O. Eisenstein, M. A. Esteruelas, C. García-Yebra, E. Gutiérrez Puebla, M. Oliván, E. Oñate, N. Ruiz, M. A. Tajada, Organometallics 1999, 18, 4949-4959; b) P. Barrio, M. A. Esteruelas, E. Oñate, Organometallics 2003, 22, 2472-2485; c) A. Álvarez-Pérez, C. González-Rodríguez, C. GarcíaYebra, J. A. Varela, E. Oñate, M. A. Esteruelas, C. Saa, Angew. Chem. Int. Ed. 2015, 54, 13357-13361.

[15] a) P. v. R. Schleyer, C. Maerker, A. Dransfeld, H. Jiao, N. J. R. v. E. Hommes, J. Am. Chem. Soc. 1996, 118, 6317-6318; b) Z. Chen, C. S. Wannere, C. Corminboeuf, R. Puchta, P. v. R. Schleyer, Chem. Rev. 2005, 105, 3842-3888; c) H. Fallah-Bagher-Shaidaei, C. S. Wannere, C. Corminboeuf, R. Puchta, P. v. R. Schleyer, Org. Lett. 2006, 8, 863.

[16] a) R. Herges, D. Geuenich, J. Phys. Chem. A 2001, 105, 3214-3220; b) D. Geuenich, K. Hess, F. Köhler, R. Herges, Chem. Rev. 2005, 105, 3758-3772.

[17] The identity of 7 was confirmed by its independent preparation from 2 and ethyl 4hydroxycrotonate (see Supporting Information).

[18] a) S. Bajo, M. A. Esteruelas, A. M. López, E. Oñate, Organometallics 2011, 30 , 5710-5715; b) S. Bajo, M. A. Esteruelas, A. M. López, E. Oñate, Organometallics 2014, 33, 1851-1858; c) S. Bajo, M. A. Esteruelas, A. M. López, E. Oñate, Organometallics 2014, 33, 4057-4066.

[19] M. P. Muñoz, Org. Biomol. Chem. 2012, 10, 3584-3594.

[20] S. Saito, N. Dobashi, Y.Wakatsuki, Chem. Lett. 2005, 34, 504-505. 
[21] Z. Zhang, S. D. Lee, A. S. Fisher, R. A. Widenhoefer, Tetrahedron 2009, 65, 1794-1798.

\section{Table of Contents}

Osmacyclopropenefuran bicycles show significant $\sigma$-aromaticity at the unsaturated three-membered ring and can play a main role in the hydration of functionalized allenes, depending on the $\mathrm{L}_{n} \mathrm{O}$ s unit.
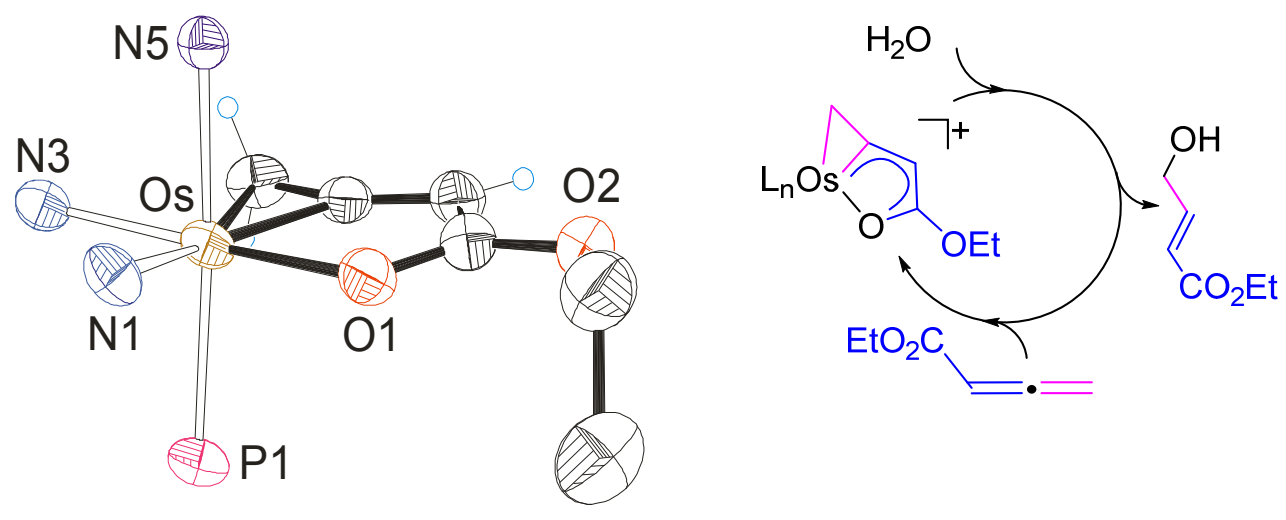

$\mathrm{L}_{\mathrm{n}} \mathrm{Os}=\mathrm{OsTp}\left(\mathrm{P}^{\mathrm{i}} \mathrm{Pr}_{3}\right)$

$\mathrm{L}_{n} \mathrm{Os}=\mathrm{OsH}(\mathrm{CO})\left(\mathrm{P}^{\mathrm{i}} \mathrm{Pr}_{3}\right)_{2}$ 